\title{
Long-Term Durability and Reactivation of Thermochemical Heat Storage Driven by the $\mathrm{CaO} / \mathrm{Ca}(\mathrm{OH})_{2}$ Reversible Reaction
}

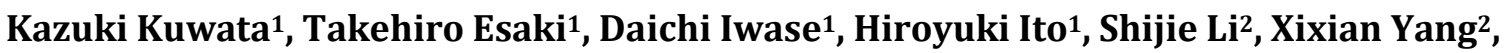 \\ Hongyu Huang'2, Noriyuki Kobayashi ${ }^{*}$
}

${ }^{1}$ Nagoya University, Nagoya, Japan

${ }^{2}$ Integrated Technology Center, Guangzhou Institute of Energy Conversion, Chinese Academy of Sciences, Guangzhou, China

Email: *kobayashi@energy.gr.jp

How to cite this paper: Kuwata, K., Esaki, T., Iwase, D., Ito, H., Li, S.J., Yang, X.X., Huang, H.Y. and Kobayashi, N. (2017) Long-Term Durability and Reactivation of Thermochemical Heat Storage Driven by the $\mathrm{CaO} / \mathrm{Ca}(\mathrm{OH})_{2}$ Reversible Reaction. Journal of Materials Science and Chemical Engineering, 5, 23-32.

https://doi.org/10.4236/msce.2017.511003

Received: October 17, 2017

Accepted: November 11, 2017

Published: November 14, 2017

Copyright $\odot 2017$ by authors and Scientific Research Publishing Inc. This work is licensed under the Creative Commons Attribution International License (CC BY 4.0).

http://creativecommons.org/licenses/by/4.0/

\begin{abstract}
Thermochemical heat storage is a promising technology for improving thermal energy efficiency. To investigate the durability of the $\mathrm{CaO} / \mathrm{Ca}(\mathrm{OH})_{2}$ reaction and develop a reactivation method, repetitive charging/discharging operation of a packed bed reactor with a thick packed bed was conducted, and variations in the discharging behavior, final conversion, and reactant activity were investigated. Owing to the formation of a deactivated sintered reactant block, the discharging time halved and the final conversion ratio decreased by the 53rd discharging operation. To enhance durability, a reactivation method using high-pressure vapor was implemented during the 54th discharging operation. Following reactivation, the final conversion increased $15 \%$, and the discharging time tripled when compared with the discharging operation before reactivation, confirming the success of this simple reactivation method.
\end{abstract}

\section{Keywords}

Thermochemical Heat Storage, Durability, Repetitive Reaction, Reactivation, $\mathrm{CaO} / \mathrm{Ca}(\mathrm{OH})_{2}$ Reaction

\section{Introduction}

Thermochemical heat storage systems have a high potential for energy saving owing to their high heat storing capacity and low heat loss [1] [2]. The chemical system explored in this study is based on the $\mathrm{CaO} / \mathrm{Ca}(\mathrm{OH})_{2}$ reversible reaction, as shown in Equation (1), which involves low cost and environmentally friendly materials. As this reaction can theoretically store heat at over $400^{\circ} \mathrm{C}$ and release it at the same or higher level, it is suitable for high-temperature applications, 
such as solar power plants, ceramics, and engines.

$$
\mathrm{CaO}+\mathrm{H}_{2} \mathrm{O} \rightleftharpoons \mathrm{Ca}(\mathrm{OH})_{2}+104.4 \mathrm{~kJ} / \mathrm{mol} .
$$

Repetitive durability is one of the main technical challenges to achieve practical application of thermochemical heat storage using gas-solid reactions. Although $1000-10,000$ stable charging/discharging operations are generally considered suitable for practical applications, reactant deactivation by sintering remains a concern for reactions requiring high charging temperatures, such as $\mathrm{MgO} / \mathrm{Mg}(\mathrm{OH})_{2}$, [3] $\mathrm{CaO} / \mathrm{Ca}(\mathrm{OH})_{2}$, and $\mathrm{CaO} / \mathrm{CaCO}_{3}$, [4] as sintering leads to the formation of granulated and densified reactant particles and the disappearance of surface structures.

Compared with $\mathrm{MgO} / \mathrm{Mg}(\mathrm{OH})_{2}$ and $\mathrm{CaO} / \mathrm{CaCO}_{3}$, the $\mathrm{CaO} / \mathrm{Ca}(\mathrm{OH})_{2}$ reaction exhibits superior repetitive durability, as constant reaction rates and final conversions have been confirmed over 50 - 100 repetitions using small-scale thermogravimetric analysis [5] [6] [7]. However, durability remains problematic, as various factors affect the sintering rate, including the state of the packed bed and the charging/discharging conditions, such as packing density, particle size, temperature, atmospheric gas species, gas pressure, and reaction time. For instance, in practical large-scale reactors, the reactant particles are generally fixed as a packed bed with a certain thickness, often resulting in longer charging/discharging times that those in thermogravimetric analysis. Therefore, it is important to secure durability in larger scale reactor. In previous studies, repetitive durability has been evaluated for 6 - 100 repetitions in $14-420$ g reactors [8] [9] [10] [11] [12]. Although some studies have reported no degradation, others have reported decreases in the reaction rate or maximum packed bed temperature [8] [13]. However, few studies have reported reactant state changes, variations in discharging behavior, or causes of degradation [9] [14]. Hence, further investigations are necessary on a larger scale with more repetitions to ensure repetitive durability of thermochemical heat storage.

Moreover, a simple and effective method to resolve deactivation is needed. Novel materials such as $\mathrm{CaTiO}_{3}$ composites, [10] porous-carbon-supported $\mathrm{CaO}$, [9] and vermiculite-supported $\mathrm{CaO}$ [7] have shown some effectiveness for improving durability, but further development is required. This study focused on the reactivation using hydration/dehydration treatment that has been reported in desulfurization and decarbonation studies [11] [12] [15]. The reported reactivation mechanism using water vapor involves crack emanation in the deactivated layer of $\mathrm{CaO}$ particles by a specific volume change (approximately 2 times) during the $\mathrm{CaO} \rightarrow \mathrm{Ca}(\mathrm{OH})_{2}$ reaction or pore remodeling during recrystallization [11] [12] [15].

\section{Experimental Section}

\subsection{Repetitive Experiments with the Packed Bed Reactor}

Figure 1 shows the experimental apparatus, which consists of a steam boiler and reactor in an electric furnace. The stainless-steel reactor was cylindrical in shape 


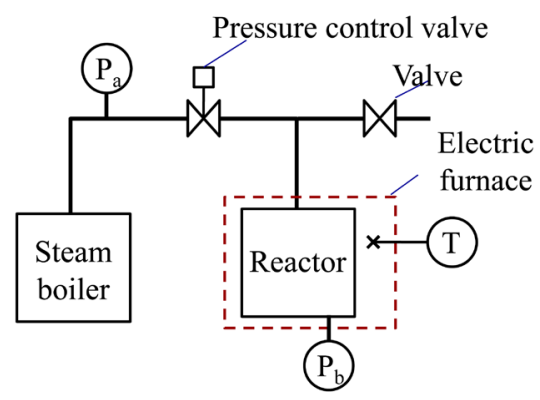

(a)

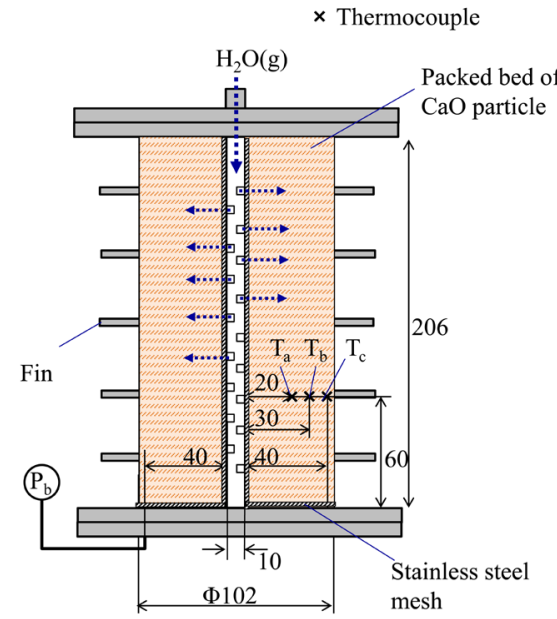

(b)

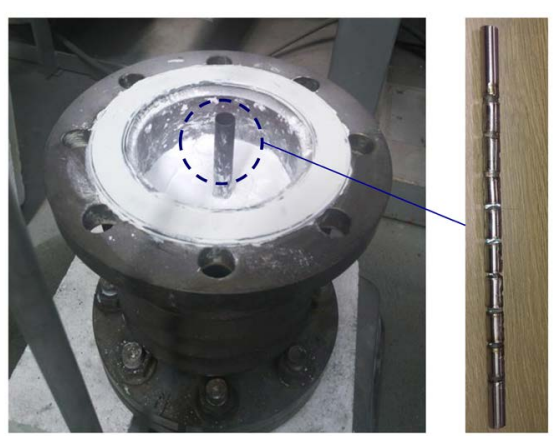

(c)

Figure 1. Schematic of the experimental apparatus for repetitive experiments: (a) schematic of the experimental apparatus; (b) details of the reactor, and (c) a photograph of the reactor and central pipe.

with an interior reactant packed bed. The packed bed consisted of $1 \mathrm{~kg}$ of $\mathrm{Ca}(\mathrm{OH})_{2}$ powder $\left(>96 \%\right.$ purity, $\left.d_{\mathrm{p} 50}=39 \mu \mathrm{m}\right)$ obtained from Kanto Kagaku (Japan). Three thermocouples were located in the packed bed at a height of $60 \mathrm{~mm}$ and at 30,40, and $50 \mathrm{~mm}$ from the center of the reactor. A pressure sensor was placed at the bottom of the reactor, $50 \mathrm{~mm}$ from the center. The vapor pipe placed at the axial center of the reactor had 17 holes ( $5 \mathrm{~mm}$ in diameter) for vapor transfer to allow transfer of the supplied vapor through the packed bed in the radial direction during the discharging operations. To avoid particle entrainment in the pipe, the central vapor pipe and reactor bottom were covered with stainless steel mesh (1 mm in thickness).

Table 1 summarizes the experimental conditions for the repetitive experiments. Those conditions were selected assuming the practical operation for charging heat over $500^{\circ} \mathrm{C}$ and discharging heat at the same level. The discharging/charging operation was conducted 59 times in total. The temperature was controlled by an electric furnace (11 kW rated output) and a proportional-integral-differential (PID) controller. During the discharging operation, the air temperature around the reactor was controlled at $220^{\circ} \mathrm{C}$ to avoid vapor condensation. The vapor was supplied to the reactor and an exothermic reaction 
Table 1. Experimental conditions for the repetitive experiments.

\begin{tabular}{ccc}
\hline Repetition & Discharging & Charging \\
\hline \multirow{2}{*}{ 1st to 53rd } & Temperature/Pressure/Time & Temperature/Pressure/Time \\
54th (Reactivation) & $220^{\circ} \mathrm{C} / 150 \mathrm{kPa} / 60-90 \mathrm{~min}$ & $550^{\circ} \mathrm{C} /$ atmospheric air $/>10 \mathrm{~h}$ \\
55th to 59th & $220^{\circ} \mathrm{C} / 300 \mathrm{kPa} / 60-90 \mathrm{~min}$ & $550^{\circ} \mathrm{C} /$ atmospheric air $/>10 \mathrm{~h}$ \\
& $220^{\circ} \mathrm{C} / 150 \mathrm{kPa} / 60-90 \mathrm{~min}$ & $550^{\circ} \mathrm{C} /$ atmospheric air $/>10 \mathrm{~h}$ \\
\hline
\end{tabular}

subsequently occurred, with the heat of the reaction was released to the air outside the reactor. The normal pressure of the supplied vapor was $150 \mathrm{kPa}$, however, during the 54th discharging operation, the pressure was $300 \mathrm{kPa}$ for the reactivation operation. During the charging operation, the temperature of the electric furnace was controlled at $550^{\circ} \mathrm{C}$. Water vapor was desorbed from the reactant under atmospheric conditions during the endothermic reaction. The charging operation for each of the 59 cycles was over $10 \mathrm{~h}$.

The temperature of the packed bed was measured with the thermocouples during discharging operation. The reactor weight was measured before and after the 1st, 12th, 32nd, 50th, and 56th discharging operations, and the final hydration conversion was calculated from each weight change.

\subsection{Reactant Analysis after Repetitive Reactions}

Pore analyses by gas adsorption (Belsorp-mini II, MicrotrackBel, Japan) and thermogravimetric analyses (TGA-50, Shimadzu, Japan) were carried out on the initial reactant and portions of the reactant sampled after the 50th and 56th discharging operations. The sintered samples had two particlesizes: $d_{\mathrm{p}} \geq 250 \mu \mathrm{m}$ and $d_{\mathrm{p}}=2 \mathrm{~mm}$, which were sampled from the reactor at packed bed heights of $100 \mathrm{~mm}$ and $20 \mathrm{~mm}$ from the central pipe. The larger reactants were not subjected to investigations owing to the limitations of the analysis equipment.

Initially, in the thermogravimetric analysis, dehydration was conducted in a dry nitrogen atmosphere at $500^{\circ} \mathrm{C}$ for $30 \mathrm{~min}$. Subsequently, hydration was conducted at a partial water vapor pressure of $20 \mathrm{kPa}$ (with $80 \mathrm{kPa}$ of nitrogen) at $220^{\circ} \mathrm{C}$.

\section{Results and Discussion}

\subsection{Discharging Behavior during a Single Operation}

The discharging behavior during repetitive reaction experiments was examined for the $\mathrm{CaO} / \mathrm{Ca}(\mathrm{OH})_{2}$ reaction system over 59 charging/discharging operations in a reactor with a thick packed bed. Figure 2 shows temporal changes in temperature and pressure during a single discharging operation. The pressure reached $150 \mathrm{kPa}$ within $1 \mathrm{~min}$ and then remained constant, confirming quick vapor transfer through the packed bed (among the particles). The temperature at each measuring point began to increase instantly, reaching a maximum within 2 - 3 min of introducing the vapor. Then, the temperature at each measuring point 


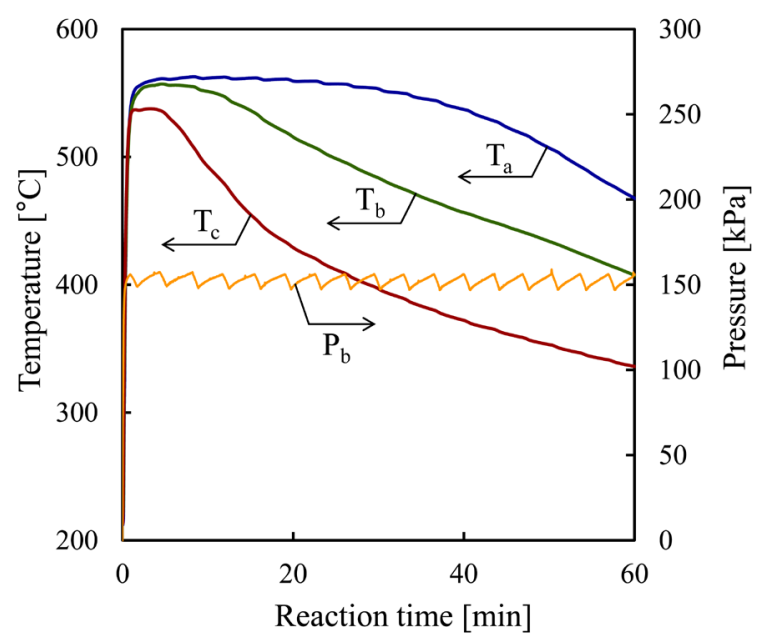

Figure 2. Temporal changes in temperature and pressure during the 12th discharging operation.

decreased in order of the distance to the reactor wall, indicating a thermal gradient in the radial direction. The maximum temperature difference of $167^{\circ} \mathrm{C}$ between $T_{\mathrm{a}}$ and $T_{\mathrm{c}}$ indicates that thermal resistance in the packed bed profoundly affects the discharging behavior. Similar mass and heat transfer trends were observed for all discharging operations.

\subsection{Effect of Sintering during Repetitive Reactions}

The extent of reactant sintering was examined during repetitive reactions. Figure 3(a) shows the initial reactant and Figure 3(b) and Figure 3(c) show the reactant after the 50th discharging operation at the upper part of the packed bed and at a height of $100 \mathrm{~mm}$, respectively. The initial small particles $\left(d_{\mathrm{p} 50}=39 \mu \mathrm{m}\right.$, Figure 3(a)) formed larger reactant blocks because of sintering, with larger particles observed at the deeper point (maximum block sizes of $10-20 \mathrm{~mm}$ (Figure $3(\mathrm{~b})$ ) and $50 \mathrm{~mm}$ (Figure $3(\mathrm{c})$ ). The filling ratio of the deeper point might be larger than that at the upper part owing to the large packed bed height, which would result in increased sintering because of the greater coordination number of the particles.

The state and reactivity changes of the reactant during the repetitive reactions were evaluated using pore and thermogravimetric analyses. As shown in Figure 4 , the pore volume and Brunauer-Emmett-Teller (BET) specific surface area decreased after repetitive reactions. This result indicated the extent of the sintering process, with a greater extent of sintering observed for larger particles. The reactivities of the sintered and initial reactants, as measured by thermogravimetric analysis, are compared in Figure 5. A degradation effect was observed for the larger sampled reactant $\left(d_{\mathrm{p}}=2 \mathrm{~mm}\right)$, but not for the smaller sampled reactant $\left(d_{\mathrm{p}} \geq 250 \mu \mathrm{m}\right)$. The time required to reach a conversion of 0.8 was about six times longer for the sintered particle than for the initial reactant. This decreased reaction rate is likely due to hindered mass transfer in the particle caused by 

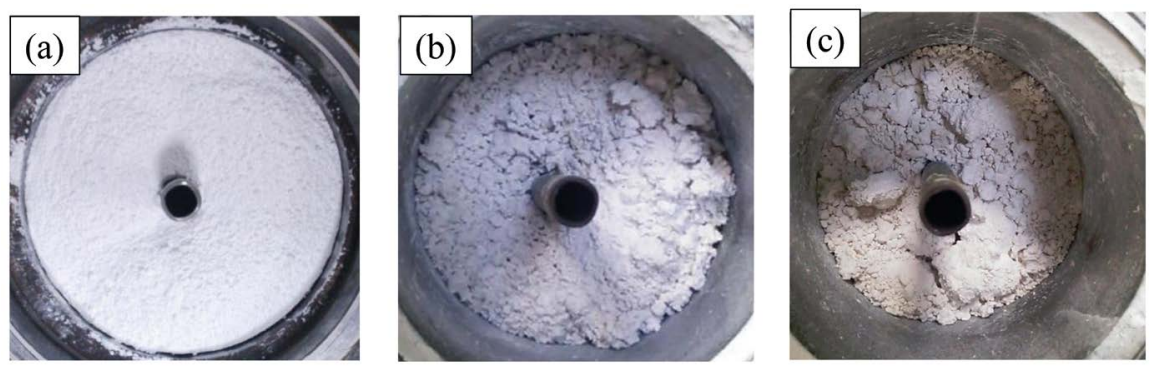

Figure 3. Reactant in the reactor (a) before the repetitive experiments and (b) at the upper part of the packed bed and (c) at a height of $100 \mathrm{~mm}$ after the 50th discharging operation.

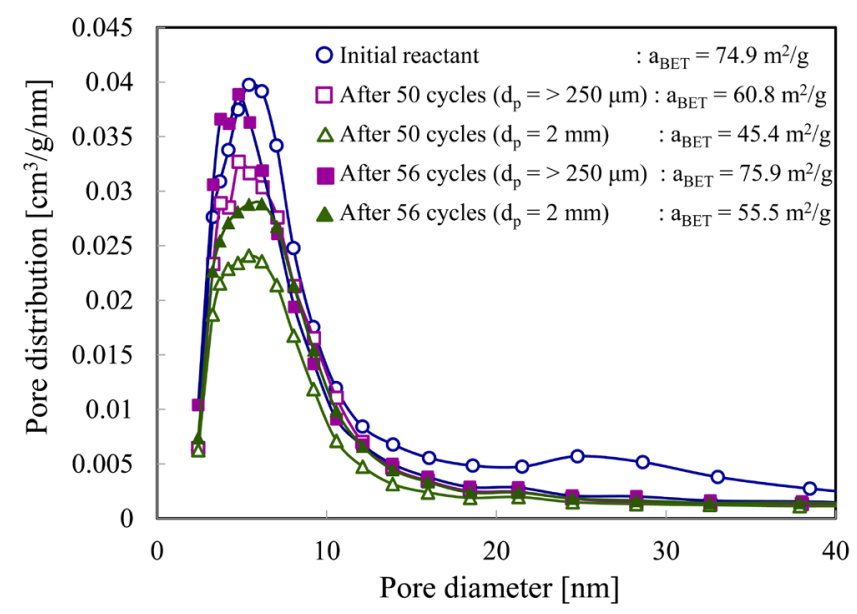

Figure 4. Gas pore analysis of reactants.

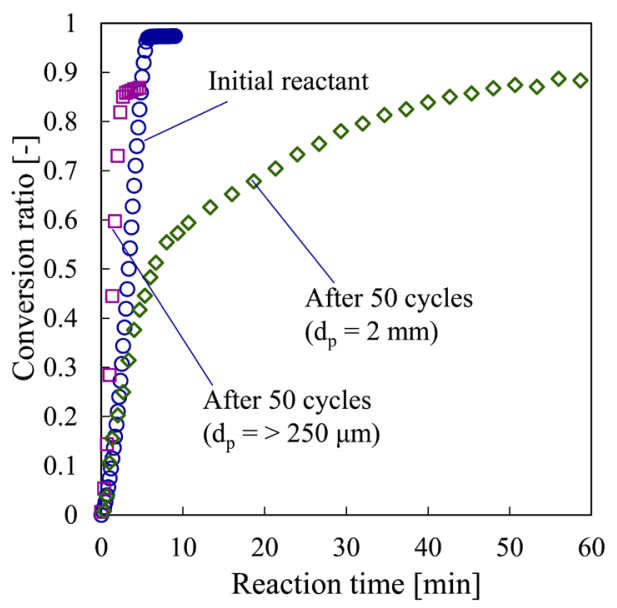

Figure 5. Thermogravimetric analysis of reactants.

granulation and densification. Therefore, deactivation by sintering during repetitive reactions was confirmed, especially for larger particles. As the analyzed sample had a particle size of $2 \mathrm{~mm}$, the larger reactant blocks in the reactor are likely to have lower reactivity, however, further research is necessary to understand specific changes in the reactants. 


\subsection{Variation in Discharging Behavior}

Figure 6 shows temporal changes in $T_{\mathrm{a}}$ during various discharging operations. Although the temperature decrease began sooner as the repetition number increased, the maximum temperature was reached at almost the same time for each operation. To examine this trend in detail, the "discharging time" was defined as the time over which $T_{\mathrm{a}} \geq 500^{\circ} \mathrm{C}$ was maintained. The discharging time during the repetitive reactions varied between 48 and 60 min during the 2nd to 17th discharging operations, monotonically decreased during the 18th to 30th discharging operations, and then fluctuated between 17 and 36 min during the 30th to 53rd discharging operations (Figure 7). Although the reaction time of each discharging operation was not equivalent, the final hydration conversion tended to decrease with increasing repetition number (Figure 8). The conversion during the 50th discharging operation (in $60 \mathrm{~min}$ ) was $22 \%$ lower than that during the first discharging operation (in $60 \mathrm{~min}$ ), whereas the conversion during the 32nd discharging operation (in $90 \mathrm{~min}$ ) was $23 \%$ lower than that during the 12th discharging operation (in $80 \mathrm{~min}$ ).

The discharging behavior of thermochemical heat storage systems is determined by three phenomena in the packed bed: mass transfer, heat transfer, and reaction of the particles. As mass transfer of vapor in the packed bed was observed to progress instantly during each discharging operation, mass transfer did not affect the repetitive behavior. Because deactivation of the reactant particles by sintering was observed, it can be concluded that the decreasing trends in discharging time and final conversion are caused by deactivation.

Sintering might also affect the characteristics of the packed bed that could change the heat transfer rate in the reactor. However, this is likely not the main reason for the observed discharging behavior, as in this case, increased discharging time with decreased conversion or vice versa would be expected.

\subsection{Reactivation with High-Pressure Vapor}

A hydration/dehydration treatment using high-pressure vapor was proposed as a reactivation method during thermochemical heat storage based on the $\mathrm{CaO} / \mathrm{Ca}(\mathrm{OH})_{2}$ reversible reaction. The reactivation operation was conducted by increasing the vapor pressure from 150 to $300 \mathrm{kPa}$ during the 54th discharging operation. The discharging time during the 54th discharging operation was short (17 min, Figure 7), however, the maximum temperature was higher than that in other operations because of differences in the equilibrium temperature. After this reactivation process, the discharging time increased to over 50 min during the 55th to 59th discharging operations at a vapor pressure of $150 \mathrm{kPa}$. Additionally, the final hydration conversion increased to 0.77 for the 56th discharging operation (Figure 8), which was $15 \%$ higher than that of the 32nd discharging operation with the same reaction time. Additionally, after reactivation, the pore volume and specific surface area of the sampled reactant increased (Figure 4). It is inferred from these results that the hydration/dehydration process with 


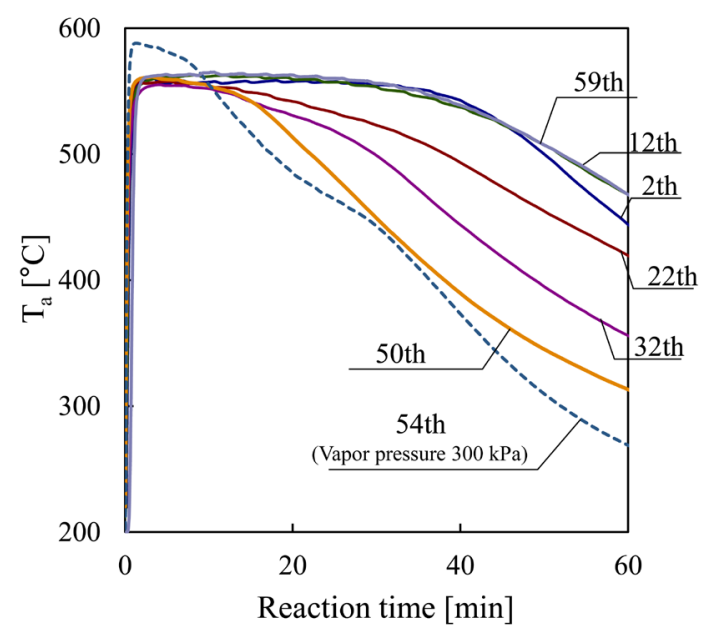

Figure 6. Variation in temperature during repetitive reactions.

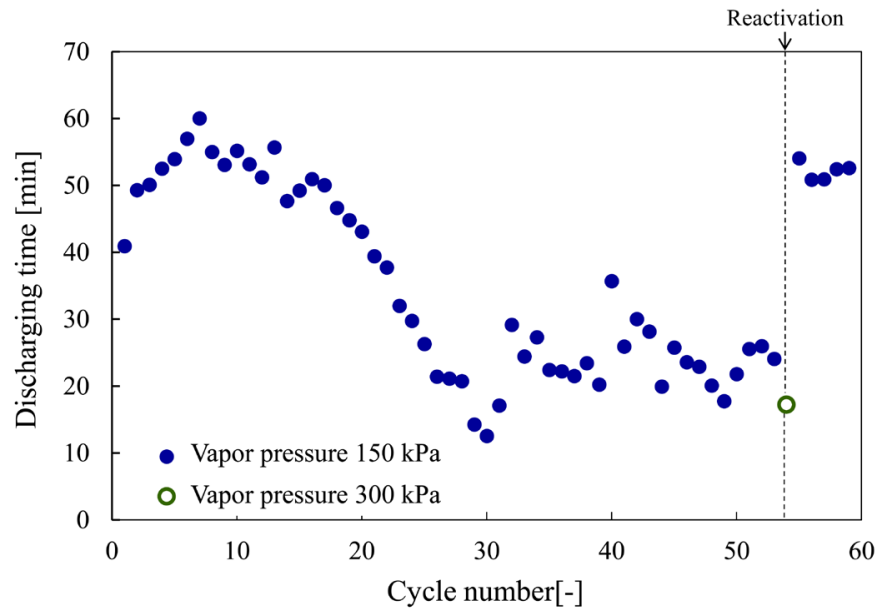

Figure 7. Variation in discharging time $\left(T_{\mathrm{a}} \geq 500^{\circ} \mathrm{C}\right)$ during repetitive reactions.

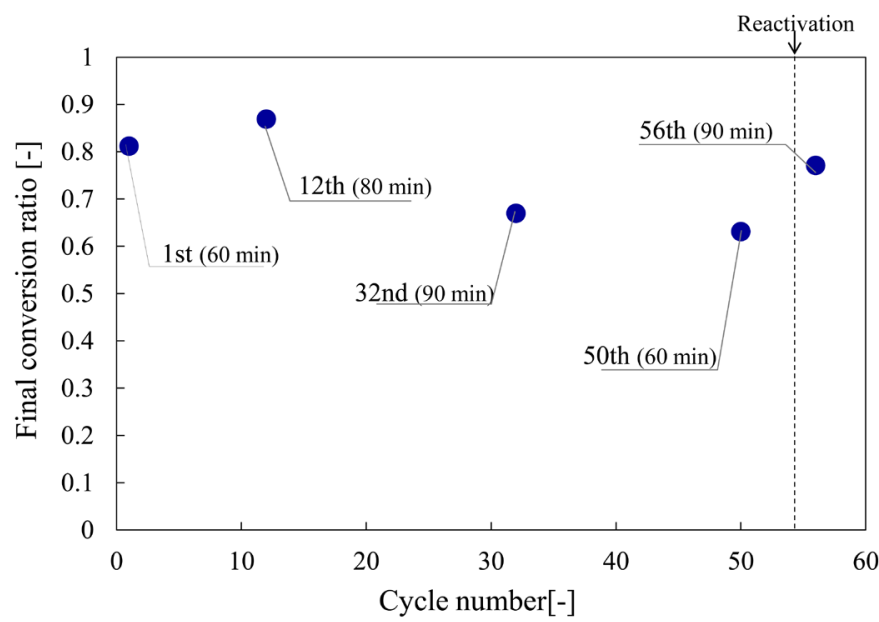

Figure 8. Variation in final hydration conversion during repetitive reactions. 
high-pressure vapor caused a reactivation effect. High-pressure vapor will be transferred to the interior of sintered particles, which might increase activation phenomena that are hindered by high vapor transfer resistance at the lower operating vapor pressure.

\section{Conclusions}

Repetitive reaction experiments in a packed bed reactor of $\mathrm{CaO} / \mathrm{Ca}(\mathrm{OH})_{2}$ were conducted to investigate durability and to demonstrate a novel reactivation method using high-pressure vapor. The following results were obtained in this study.

1) Sintering of the reactant particles occurred during the repetitive reactions. The sintered reactant had a lower pore volume, lower specific surface area, and lower reactivity than the original reactant. Thus, reactant deactivation due to sintering was confirmed, which was the main cause of the decreasing discharging time and the final hydration conversion during 53 repetitive reactions.

2) The possibility of a novel reactivation method using high-pressure vapor was confirmed for addressing the durability problem caused by sintering of the reactant particles. Following the reactivation operation, the discharging time was similar to those during the initial cycles, and the final hydration conversion was $15 \%$ higher than that for the deactivated state. In addition, pore remodeling after the reactivation was observed.

It is necessary to analyze structural and distributional changes of the reactant particles and packed bed during respective charging/discharging operations for explaining the detail effect of the sintering and potential of the proposed reactivation method. The exhaustive study will conduct in the future. However, this study makes a significant contribution for the development of durable systems for thermochemical heat storage.

\section{Acknowledgements}

This research work was supported by Thermal Management Material and Technology Research supported by Ministry Development Organization (NEDO) and TherMAT, Future Pioneering Projects of METI, Japan. We also would like to thank Editage (https://www.editage.jp/) for English language editing.

\section{References}

[1] Abedin, A.H. and Rosen, M.A. (2011) A Critical Review of Thermochemical Energy Storage Systems. The Open Renewable Energy Journal, 4, 42-46. https://doi.org/10.2174/1876387101004010042

[2] Cot-Gores, J., Castell, A. and Cabeza, L.F. (2012) Thermochemical Energy Storage and Conversion: A-State-Of-The-Art Review of the Experimental Research under Practical Conditions. Renewable and Sustainable Energy Reviews, 16, 5207-5224. https://doi.org/10.1016/j.rser.2012.04.007

[3] Kato, Y., Saito, T., Soga, T., Ryu, J. and Yoshizawa, Y. (2007) Durable Reaction Material Development for Magnesium Oxide/Water Chemical Heat Pump. Journal of 
Chemical Engineering of Japan, 40, 1264-1269. http://doi.org/10.1252/jcej.07WE218

[4] Kubota, M., Yokoyama, K., Watanabe, F., Kobayashi, N. and Hasatani, M. (2001) Heat Releasing and Recovering Characteristics of $\mathrm{CaO} / \mathrm{CaCO}_{3}$ Type High Temperature Chemical Heat Pump with Packed Bed Reactor. Kagaku KogakuRonbunshu, 27, 285-287. http://doi.org/10.1252/kakoronbunshu.27.285

[5] Schaube, F., Koch, L., Wörner, A. and Müller-Steinhagen, H. (2012) A Thermodynamic and Kinetic Study of the De- and Rehydration of $\mathrm{Ca}(\mathrm{OH})_{2}$ at $\mathrm{High}_{2} \mathrm{O}$ Partial Pressures for Thermo-Chemical Heat Storage. Thermochimica Acta, 538, 9-20. https://doi.org/10.1016/j.tca.2012.03.003

[6] Iwase, D., Kobayashi, N., Esaki, T., Kita, H. and Yamashita, S. (2015) Basic Study on Development of Heat Storage Technology at $500^{\circ} \mathrm{C}$ Using $\mathrm{Ca}(\mathrm{OH})_{2}$. Proceedings of the 34th Annual Meeting of Japan Society of Energy and Resources, Tokyo, 9-10 June 2015, 15-16.

[7] Kariya, J., Ryu, J. and Kato, Y. (2016) Development of Thermal Storage Material Using Vermiculite and Calcium Hydroxide. Applied Thermal Engineering, 94, 186-192. https://doi.org/10.1016/j.applthermaleng.2015.10.090

[8] Matsuda, H., Lee, S.K., Ishizu, T. and Hasatani, M. (1987) Heat-Release Characteristics of $\mathrm{CaO}$ Packed Bed Accompanied by Exothermic Hydration. Kagaku KogakuRonbunshu, 13, 20-28. http://doi.org/10.1252/kakoronbunshu.13.20

[9] Watanabe, F., Tsumagari, S., Huang, H., Hasatani, M., Kobayashi, N., Tsubouchi, O., and Shiomi, N. (2013) Performance Evaluation of Carbonaseous Porous Solid Supported $\mathrm{Ca}(\mathrm{OH})_{2}$ Chemical Heat Storage Material. Kagaku KogakuRonbunshu, 39, 378-383. http://doi.org/10.1252/kakoronbunshu.39.378

[10] Aihara, M., Nagai, T., Matsushita, J., Negishi, Y. and Ohya, H. (2001) Development of Porous Solid Reactant for Thermal-Energy Storage and Temperature Upgrade Using Carbonation/Decarbonation Reaction. Applied Energy, 69, 225-238. https://doi.org/10.1016/S0306-2619(00)00072-6

[11] Watanabe, T., Hayashi, M., Matsuda, H. and Hasatani, M. (1993) Enhancement of Reactivity of $\mathrm{CaO}$ Produced from Limestone by Means of Hydration-Dehydration Treatments. Kagaku KogakuRonbunshu, 19, 91-98. https://doi.org/10.1252/kakoronbunshu.19.91

[12] Yu, F.-C., Phalak, N., Sun, Z. and Fan, L.-S. (2012) Activation Strategies for Calcium-Based Sorbents for $\mathrm{CO}_{2}$ Capture: A Perspective. Industrial \& Engineering Chemistry Research, 51, 2133-2142. https://doi.org/10.1021/ie200802y

[13] Kito, T. and Kobayashi, N. (2012) Evaluation of Output Power Characteristics of Chemical Heat Pump by Using CaO-LiCl Compound Reactant. Kagaku KogakuRonbunshu, 38, 172-175. https://doi.org/10.1252/kakoronbunshu.38.172

[14] Schaube, F., Kohzer, A., Schütz, J., Wörner, A. and Müller-Steinhagen, H. (2013) De- and Rehydration of $\mathrm{Ca}(\mathrm{OH})_{2}$ in a Reactor with Direct Heat Transfer for Thermo-Chemical Heat Storage. Part A: Experimental Results. Chemical Engineering Research and Design, 91, 856-864. https://doi.org/10.1016/j.cherd.2012.09.020

[15] Hughes, R.W., Lu, D., Anthony, E.J. and Wu, Y. (2004) Improved Long-Term Conversion of Limestone-Derived Sorbents for In Situ Capture of $\mathrm{CO}_{2}$ in a Fluidized Bed Combustor. Industrial \& Engineering Chemistry Research, 43, 5529-5539. https://doi.org/10.1021/ie034260b 